\title{
Utilization of Jigsaw Cooperative Learning Strategy on Maternity Nursing Students' Attitude and Achievement
}

\author{
Rehab Soliman Abd El Aliem ${ }^{1,}$, , Samah Said Sabry², Hedya Fathy MohyEl-Deen² \\ ${ }^{1}$ Obstetrics and Woman's Health Nursing, Faculty of Nursing, Benha University, Benha, Egypt \\ ${ }^{2}$ Community Health Nursing, Faculty of Nursing, Benha University, Benha, Egypt
}

Email address:

rehab.abdelalim@fnur.bu.edu.eg (R. S. A. El Aliem)

${ }^{*}$ Corresponding author

\section{To cite this article:}

Rehab Soliman Abd El Aliem, Samah Said Sabry, Hedya Fathy Mohy. Utilization of Jigsaw Cooperative Learning Strategy on Maternity Nursing Students' Attitude and Achievement. American Journal of Nursing Science. Vol. 8, No. 6, 2019, pp. 361-370.

doi: 10.11648/j.ajns.20190806.22

Received: October 29, 2019; Accepted: December 2, 2019; Published: December 27, 2019

\begin{abstract}
Background: cooperative jigsaw learning strategy is a kind of cooperative learning method which has been claimed to minimize the competitiveness in the learning environment by encouraging students for cooperative work. Aim of the present study was to evaluate the effect of the utilization cooperative jigsaw learning strategy on maternity nursing students' attitudes and achievements. Research design: A quasi-experimental study was utilized. Sample: A convenient sample of 310 participants recruited from third-year nursing students at the faculty of nursing at Benha University during the course entitled maternal and newborn health nursing in the academic year 2018-2019. Those students were divided into two groups, control group (160) "lecture group" and study group (150) "jigsaw group". Tools of data collection; 1) self-administered questionnaire, 2) Learning's achievement tool (before and after intervention), 3) Likert attitude scale, 4) cooperative jigsaw opinion sheet, in addition to supportive material related to jigsaw strategy. Results: there were statistically significant differences between jigsaw and lecture groups regarding learning achievements immediately after intervention as $p$ value $\leq 0.05$, also there were statistically significant differences between both groups in follow up test with p-value $\leq 0.001$. Additionally, the students in the jigsaw group exhibited a more positive attitude regarding the jigsaw strategy than the students in the lecture group. Conclusion: The jigsaw learning strategy is effective in enhancing maternity nursing students' attitudes and achievements during maternal and newborn health nursing course. Recommendations: Apply cooperative jigsaw learning strategy as a teaching method in nursing student curriculums. Further research is still needed to study the effect of jigsaw learning strategy on clinical achievement.
\end{abstract}

Keywords: Cooperative Jigsaw Learning Strategy, Learning Achievement, Students’ Attitude

\section{Introduction}

The primary objective of teaching strategies in maternal health education is improving academic achievements, training successfully and motivating nursing students toward professional competence so that they can explore knowledge for problem-solving in their profession [1]. Accordingly, professional competency in teaching and learning environment is influenced by factors such as the type of educational content and teaching strategies that can enhance cooperative \& effective learning and academic achievements to maternity students [2].
Cooperative learning is one kind of student teaching approaches. It has been documented throughout the literature as effective in helping students obtain practical learning skills, effective communication, and proficiency in terms of understanding knowledge, and promoting positive student attitudes towards their learning [3]. Recently, there have been efforts to implement student-centered approaches in an attempt to provide students with an interactive approach, to try and make better learning achievements [4].

In traditional learning, the majority of interactions are 
teacher-student channels. Which can create a competitive environment and produce a passive attitude toward learning as students vie for the teacher's approval rather than developing cooperative learning [5]. One alternative teaching strategy to lecture-based teaching is a cooperative jigsaw learning strategy, a kind of cooperative learning method. This approach has been claimed to minimize the competitiveness in the learning environment by encouraging students for cooperative work. Besides, it is claimed to promote more positive student attitudes toward their learning, enhance more positive relationships between students, develop self-esteem and cohesiveness, and improve learning skills [6]. Cooperative Jigsaw strategy integrates students to get involved with their course materials, preparation, and presentation and encourages peer learning. The technique is done with the support and guidance of the teachers, thus activating positive student's attitude instincts; it also helps the students to create peer support, develop critical thinking, deal with their group members and provides equal opportunities to engage in thinking and problem solving [7].

In Jigsaw, the teachers divide the academic material into subtopics and the students are assigned to member teams to work on academic material and read its given subtopic. Then members of different teams who have studied the same sections meet in expert" Jigsaw" groups to discuss their sections. Next, the students return to their teams and take turns teaching their teammates about their sections as described in figure 1. Just like a jigsaw puzzle, each piece (Student part) is essential for the completion and full understanding of the final product thus each student is essential hence the jigsaw teaching strategy is effective [8]. Since the only way students can learn sections other than their own is to listen carefully to their teammates, they are motivated to support and show interest in one another's work. The students take individual quizzes, which result in team scores. The teacher floated between groups and facilitated the whole process [9].

Jigsaw is a well-established method for encouraging group sharing and learning of specific content. This technique used as an instructional activity across several days and is best to use when there is a large amount of content to teach and even a large number of students to learn, as it broke the content into subtopics and the students into small groups work for cooperative learning [10].

Cooperative the jigsaw strategy has been used in other areas of education, including nursing education and most students found it to be a useful learning experience put them in the active learning situation, communicating ideas, develop critical thinking and problem-solving skills [11]. Maternal and newborn health nursing courses prepare nursing students to work with mothers and their infants in an intensive working environment. Those who want to work in maternity nursing must have a high level of advanced specific knowledge \& practices to perform their jobs [12]. Jigsaw as a learning strategy has shown to improve long-term retention of acquired knowledge among students due to active engagement in the learning process. Also, students' decision-making and problem-solving, critical thinking skills independently improved. As well, these criteria need to be provided in maternity nursing, to be able to achieve the mother and neonate safety [13].

\subsection{Significant of the Study}

The dominant educational method at most universities is in the form of a lecture that $80 \%$ of educational content is forgotten within 8 weeks [14]. Teachers like to use lectures because it can be applied in large classes or due to a large number of educational topics or limited time. However, it is the one-way teaching and can quickly become boring and prevent the effective learning of students. The presence of qualified, competent, cooperative learning methods for maternity nursing students will make them deliver highquality maternity care, where nurses can be invaluable in preventing harm to mothers and improving their pregnancy outcomes. All of that requires obtaining high levels of knowledge and skills during the nursing academic period as the world today needs graduates who think critically and apply skills in complex patient care situations. Therefore, the demands for changing the traditional teaching strategies have escalated in the last decades to enable the learners to cope with these challenges and applying new teaching methods to improve critical thinking skills, problem-solving and widely acknowledge the students.

That will be reflected in students' attitudes and achievements and subsequently on the rank of the faculty among the other nursing faculties. Considering the lack of Egyptian studies that addressed jigsaw strategy in maternity specialty, therefore this study was conducted to evaluate the effect of the utilization of cooperative jigsaw learning strategy on maternity nursing students' attitudes and achievement.

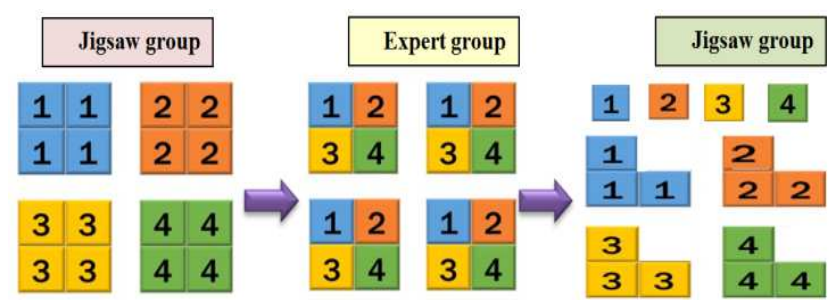

Figure 1. Jigsaw formation groups adapt from Brame C. J. \& Biel R., (2015): Setting up and facilitating group work using cooperative learning groups effectively, retrieved fromhttp://cft.vanderbilt.edu /guides-subpages/setting-up-and-facilitating-group-work-using-cooperative-learninggroups-effectively [15].

\subsection{Aim of the Study}

The present study aims to evaluate the effect of the utilization cooperative jigsaw learning strategy on maternity nursing students' attitudes and achievement.

This aim was achieved through:

1. Assess the existing level of knowledge on normal \& high -risk pregnancy lectures among maternity nursing students 
2. Plan and utilize the cooperative jigsaw learning strategy as a learning strategy for maternity nursing students related to the theoretical part of the normal \& high-risk pregnancy lectures.

3. Evaluate the attitude and achievements of maternity nursing students in both groups.

\subsection{Research Hypotheses}

1. The maternity nursing students who are subjected to Jigsaw learning strategy will have better achievement compared to their peers in the lecture group.

2. The maternity nursing students who are subjected to Jigsaw learning strategy will have a positive attitude compared to their peers in the lecture group.

\section{Subject and Methods}

\subsection{Research Design}

A quasi-experimental pre and posttest design were used.

\subsection{Setting}

The study was conducted at the faculty of nursing, Benha University during the course of maternal and newborn health nursing.

\subsection{Sampling}

A convenient sample of 310 nursing students was recruited from the third year. They are divided into two groups according to the timing of the study. Students attended the first semester for the academic year (2018-2019) were control (lecture) group ( $\mathrm{n}=160$ students) who follow the traditional method of teaching regarding normal \&high- risk pregnancy lectures, while students attended the second semester from the academic year (2018-2019) were the study (jigsaw) group ( $\mathrm{n}=150$ students) who utilize cooperative jigsaw learning strategy regarding normal \&high-risk pregnancy lectures. The study group divided into 10 heterogeneous subgroups each group includes (15) students vary in their academic abilities.

\subsection{Tools of Data Collection}

\subsubsection{A Self-administered Questionnaire}

The researchers constructed a questionnaire sheet after reviewing the related literature. It was used to assess the personal characteristics of students as age, gender, marital status, residence, and educational background (secondary or technical school). (Questions: 1 - 6). It took 5 minutes to be filled by students.

\subsubsection{Learning's Achievement Questionnaire}

It was designed by the researchers to assess the student's knowledge achievement through different strategies of learning among both control and study groups before and after the intervention. it included 35 questions (Questions: 641) regarding the theoretical content of normal \&high -risk pregnancy lectures, presenting in two parts:

Part one: consisted of 20 multiple choice questions and 5 true and false questions regarding definition, prevalence, risk factors, causes, signs symptoms, and diagnosis.

Part two: it consisted of 7 multiple choice questions and 3 true and false questions regarding antenatal care \&nursing management. It took 45 minutes to be answered by students.

Scoring system:

i. A score (1) indicates a correct answer.

ii. A score (0) indicates an incorrect answer. The total achievement scores range from $0-35$ according to the operational scoring system at the academic setting in Egypt as the following:
1. Excellent: $85 \%-100 \%$
(29.75 - 35 degree)
2. Very good: $75 \%-<85 \%$
$(26.25-<29.75$ degree)
3. Good: $65 \%-<75 \%$
4. Pass: $60 \%-<65 \%$
(22.75 - <26.25 degree)
5. Poor: $<60 \%$
$(21-<22.75$ degree)
$(<21$ degree $)$

\subsubsection{Nursing Student's Attitude Measuring Scale}

It was adapted from [16, 17] and modified by the researcher to assess nursing students' attitudes toward both methods of teaching strategies. It consists of eighteen statements with three levels of responses: disagree, uncertain and, agree. It took 10 minutes to be filled by students.

Scoring system:

Students attitude toward the currently used teaching methods was based on 3 points of Likert scale: - a score (2) for agree, a score (1) for uncertain, a score (0) for disagree. While the total score ranged from (0) to (36) then the total attitude score was classified as the following:
Negative attitude
less than $70 \%(0-24)$
Positive attitude
$70 \%-100 \%(25-36)$

\subsubsection{Cooperative Jigsaw Opinion Scale (CJOS)}

It was developed by the researcher based on the related literature [18] to assess the opinions of the study group regarding the jigsaw method of cooperative learning at the end of the study. It includes 14 statements implied their responses, positive (score 1) or negative (score 0) opinions. In addition to a handout material for the study group to describe jigsaw strategy as a teaching method including "concept of jigsaw strategy, objectives, purpose and steps"

\subsection{Validity and Reliability}

These tools were reviewed by a jury of 3 experts in the field of maternity and gynecological nursing department to test its contents. Reliability was done by Cranach's Alpha coefficient test which revealed $\mathrm{r}=0.79$ for learning's achievement questionnaire, $\mathrm{r}=0.87$ for Nursing student attitude measuring scale and $r=0.77$ for cooperative jigsaw opinion scale.

\subsection{Administrative Design and Ethical Considerations}

The necessary official approval was obtained from the Dean of the Benha Faculty of Nursing to carry out the study. 
The aim of the study was explained to each student and informed consent to participate was obtained. They were allowed to refuse to participate and they could withdraw at any stage of the research. Additionally, they were assured that the information would be confidential and used for the research purpose only without any effect on their current and future academic course assessment.

\subsection{Field Work}

The researchers first explained the aim of the study to the participants and reassure the students that information collected would be treated confidentiality. The study was carried out through the following phases; Assessment, planning, implementation, and evaluation.

\subsubsection{Assessment and Planning Phase}

It started by preparing all information regarding the concept of jigsaw strategy, the main purpose, and technique. The researchers determined the objectives of study subjects related to normal \&high-risk pregnancy lectures. Then prepared the study material and tools based on recent textbooks, research articles, websites, references, etc. the traditional strategy of teaching "Lectures" was developed for the control group. Researchers prepared theoretical content "handout" to be given to the students. Lectures designed for both groups were delivered according to (table 1) and taught through eight sessions as follows:

Table 1. Lectures of normal and high-risk pregnancy.

\begin{tabular}{l}
\hline Topics \\
\hline Physiological changes in pregnancy \\
Antenatal care \\
Diagnosis of pregnancy \\
Gestational diabetes \\
Gestational hypertension \\
Bleeding in early pregnancy \\
Bleeding in late pregnancy \\
Cardiac disorder during pregnancy
\end{tabular}

1. Also, the researchers designed the evaluation tools in this stage.

2. All students were firstly assessed for personal characteristics in the classroom by self-administered questionnaire (tool 1).

3. Students 'level of knowledge regarding normal \&highrisk lectures were assessed by using pre-test (Tool II).

4. And then the students from both groups were then informed about the time of the posttest (Immediate after intervention) and follow up exam (after four weeks of intervention).

\subsubsection{Pilot Study}

A pilot study was conducted for (17) students of the total sample size. It was conducted to evaluate the efficiency and content validity of the tool, find the possible obstacles and problems that might be faced during data collection and for the feasibility of the research process. Students included in the pilot study were excluded from the sample, to avoid contamination of the research sample.

\subsubsection{Implementation Phase}

A. For the control group (lecture group):

The Researchers presented scientific content in form of lecture for the control group in eight teaching sessions, every session was taking two hours per day, two sessions in the week and repeated for four weeks according to a predesigned schedule of the maternal and newborn health nursing course time table. The lecture was presented for students as powerpoint presentations. The researchers conducted a classroom group discussion for all students to clarify any missing point of contents. And at the end of the lecture, the main points of content were summarized.

B. For study group (Jigsaw group):

Implementation phase included four teaching sessions through 4 weeks as the following consequence:

Session 1: (orientation Session):

1. Before starting normal and high -risk pregnancy lectures, the study group attended an orientation session for two hours, to be trained on the process of jigsaw strategy as a teaching method.

2. First, the researchers (teachers) explained in detail the jigsaw as a learning strategy including its concept, objectives, steps, and benefits to the students through a lecture by using powerpoint presentations. Further, the researchers distributed an illustrated handout describing jigsaw strategy to students. Then the researchers divided students into 10 groups, each group consisted of 15 students. These were the "jigsaw groups"

3. A team leader from students was assigned to each group. Their function was to facilitate group discussions and sharing.

4. The normal \&high-risk pregnancy lectures were divided into 15 different subtopics including "Physiological and psychological changes in pregnancy, antenatal care, diagnosis of pregnancy, gestational diabetes, gestational hypertension, preeclampsia, severe preeclampsia, eclampsia, abortion, ectopic pregnancy, vesicular mole, placenta Previa, placenta abruption, anemia with pregnancy, heart disease with pregnancy.

5. Each student of the jigsaw group was assigned for one sub-topic and received a card with his subtopic, as well as a few leading questions to help them learn about their topic.

6. Next, the students who were assigned for the same sub-topics in all the 10 jigsaw groups collected to form "expert groups" as depicted in (table 2). The students were asked to prepare the subtopics for discussion in their expert group in the next session. 
Table 2. Formation of jigsaw groups and expert groups.

\begin{tabular}{|c|c|c|c|c|c|c|c|}
\hline & \multicolumn{7}{|c|}{ jigsaw groups } \\
\hline & & (A) & (B) & (C) & (D) & (E) & T0PIC \\
\hline \multirow{15}{*}{ Expert groups } & G1 & A1 & B1 & $\mathrm{C} 1$ & D1 & E1 & 1- Physiological adaptation to pregnancy \\
\hline & $\mathrm{G} 2$ & $\mathrm{~A} 2$ & B2 & $\mathrm{C} 2$ & D2 & E2 & 2- Antenatal care \\
\hline & G3 & A3 & B3 & $\mathrm{C} 3$ & D3 & E3 & 3- Diagnosis of pregnancy \\
\hline & G4 & A4 & B4 & $\mathrm{C} 4$ & D4 & E4 & 4- Gestational diabetes \\
\hline & G5 & A5 & B5 & $\mathrm{C} 5$ & D5 & E5 & 5- Gestational hypertension \\
\hline & G6 & A6 & B6 & C6 & D6 & E6 & 6- preeclampsia \\
\hline & G7 & A7 & B7 & $\mathrm{C} 7$ & D7 & E7 & 7- sever preeclampsia \\
\hline & G8 & A8 & B8 & $\mathrm{C} 8$ & D8 & E8 & 8- eclampsia \\
\hline & G9 & A9 & B9 & C9 & D9 & E9 & 9- abortion \\
\hline & G10 & A10 & $\mathrm{B} 10$ & $\mathrm{C} 10$ & D10 & E10 & 10- ectopic pregnancy \\
\hline & G11 & A9 & B9 & C9 & D9 & E9 & 11- vesicular mole \\
\hline & G12 & A12 & B12 & $\mathrm{C} 12$ & D12 & E12 & 12- placenta Previa \\
\hline & G13 & A13 & B13 & $\mathrm{C} 13$ & D13 & E13 & 13- placenta abruption \\
\hline & G14 & A14 & B14 & $\mathrm{C} 14$ & D14 & E14 & 14- Anemia with pregnancy \\
\hline & G15 & A15 & B15 & $\mathrm{C} 15$ & D15 & E15 & 15- heart disease with pregnancy \\
\hline
\end{tabular}

Table 2. Continued.

\begin{tabular}{|c|c|c|c|c|c|c|c|}
\hline & \multicolumn{4}{|c|}{ jigsaw groups } & & & \multirow[t]{2}{*}{ TOPIC } \\
\hline & & (H) & (I) & $(\mathrm{J})$ & (F) & (G) & \\
\hline \multirow{13}{*}{ Expert groups } & G1 & H1 & 1I & $1 \mathrm{~J}$ & F 1 & G1 & 1- Physiological adaptation to pregnancy \\
\hline & G2 & $\mathrm{H} 2$ & $2 \mathrm{I}$ & $2 \mathrm{~J}$ & F 2 & $\mathrm{G} 2$ & 2- Antenatal care \\
\hline & G3 & H3 & $3 \mathrm{I}$ & $3 \mathrm{~J}$ & F3 & G3 & 3- Diagnosis of pregnancy \\
\hline & G4 & $\mathrm{H} 4$ & $4 \mathrm{I}$ & $4 \mathrm{~J}$ & $\mathrm{~F} 4$ & G4 & 4- Gestational diabetes \\
\hline & G5 & H5 & $5 \mathrm{I}$ & $5 \mathrm{~J}$ & F5 & G5 & 5- Gestational hypertension \\
\hline & G6 & H6 & $6 \mathrm{I}$ & $6 \mathrm{~J}$ & F6 & G6 & 6- preeclampsia \\
\hline & G8 & H8 & $8 \mathrm{I}$ & $8 \mathrm{~J}$ & F8 & G8 & 8- eclampsia \\
\hline & G9 & H9 & 9I & $9 \mathrm{~J}$ & F9 & G9 & 9- abortion \\
\hline & G10 & $\mathrm{H} 10$ & $10 \mathrm{I}$ & $10 \mathrm{~J}$ & F10 & G10 & 10- ectopic pregnancy \\
\hline & G11 & H9 & $11 \mathrm{I}$ & $11 \mathrm{~J}$ & F9 & G9 & 11- vesicular mole \\
\hline & G12 & H12 & $12 \mathrm{I}$ & $12 \mathrm{~J}$ & F12 & G12 & 12- placenta Previa \\
\hline & G13 & H13 & $13 \mathrm{I}$ & $13 \mathrm{~J}$ & F13 & G13 & 13- placenta abruption \\
\hline & G14 & H14 & $14 \mathrm{I}$ & $14 \mathrm{~J}$ & F14 & G14 & 14- Anemia with pregnancy \\
\hline
\end{tabular}

Researchers provided the same handout given for the control group regarding normal \&high-risk pregnancy lectures to the study group. Also, the researchers suggested resources (textbooks, research articles, websites), to direct the students and help them in preparing their topics.

The groups were instructed to prepare the topic well, read them well, and do extra reading than the hand out within one week.

The researchers ensured that all information about the prepared subtopics by students was accurate and it could be corrected before the students started their discussion in front of their groups and clearing their doubts.

Session 2: (Expert groups discussion):

The expert group worked together for two hours in the next week, discussing their topics. Each student shared his acquired knowledge regarding the topics. The others noted down additional points, and clearing their doubts, if any, to the researchers (teachers).

Session 3: (jigsaw groups discussion):

The students returned to their jigsaw group again to present their subtopic to others. This session took about 2 hours so that each student could present his subtopic. Finally, they discussed topics together to improve their thinking ability, cooperation, interactions, and active learning. The researchers floated between groups and facilitated the whole process.

Session4: (cooperative learning):

The last session was of 4 hours duration during the third week, in which one student from each "jigsaw group" was randomly selected and asked to teach a particular topic to the whole class. The student was permitted to use the board. Since all topics could be discussed. The students were also encouraged to ask questions if they had any to the presenter, and the researchers clarified their inquiries.

Finally, cooperative jigsaw's opinion sheet (tool IV) was distributed to assess the study group's opinions related to the jigsaw strategy as teaching strategies.

\subsubsection{Evaluation Phase}

All the students for both groups were assessed for their achievements regarding the theoretical part of normal \& high-risk pregnancy lectures through before, after, and follow up exam by using the tool (II).

Assessment of the students' attitude regarding the two teaching strategies used among both groups was done using (tool III).

Then a comparison between two groups (jigsaw group and lecture group) was done to evaluate the effect of two teaching strategies in order to investigate the research hypotheses. 


\subsection{Statistical Analysis}

Data entry and statistical analysis were done using the Statistical Package for Social Science (SPSS), version 24.0, a statistical software package. The collected data was analyzed and results were presented in tables and graphics using frequency distribution tables. Data were presented using descriptive statistics in the form of frequencies and percentages for qualitative variables, and means and standard deviations for quantitative variables. Analytical tests were used to determine the relations; qualitative variables were compared using chisquare as the test of statistically significance and the p-value is the degree of significance. Also, the Pearson correlation (r) test was used for the association between total scores. A statistical significance was considered when $\mathrm{P}$-value $\leq 0.05$, the nonsignificance difference obtained when P-value $>0.05$, while a highly significant difference at $\mathrm{P}$-value $\leq 0.001$.

\subsection{Limitation of the Study}

1. The time limitation to implement jigsaw activity in the routine course sessions.

2. A dropout rate of 30 students in both groups because of student absenteeism during any session or due to incomplete data filled by students and were excluded.

\section{Results}

Table 3. Socio-demographic characteristics for the studied groups $(n=310)$.

\begin{tabular}{|c|c|c|c|c|c|c|}
\hline \multirow{2}{*}{ Socio-Demographic Characteristics } & \multicolumn{2}{|c|}{ jigsaw group $(n=150)$} & \multicolumn{2}{|c|}{ Lecture group $(\mathrm{n}=160)$} & \multirow{2}{*}{$\mathrm{X}^{2}$} & \multirow{2}{*}{ p-value } \\
\hline & No & $\%$ & No & $\%$ & & \\
\hline \multicolumn{7}{|l|}{ Age } \\
\hline Mean \pm SD & \multirow{2}{*}{\multicolumn{2}{|c|}{$20.8 \pm 0.54$}} & \multirow{2}{*}{\multicolumn{2}{|c|}{$20.8 \pm 6.53$}} & \multirow[t]{2}{*}{10.57} & \multirow[t]{2}{*}{$0.027^{\mathrm{ns}}$} \\
\hline Gender & & & & & & \\
\hline Female & 110 & 73.3 & 123 & 76.9 & \multirow{3}{*}{1.43} & \multirow{3}{*}{$0.23^{\text {ns }}$} \\
\hline Male & 40 & 26.7 & 37 & 23.1 & & \\
\hline \multicolumn{5}{|l|}{ Marital Status } & & \\
\hline Single & 145 & 96.7 & 146 & 91.2 & \multirow{3}{*}{0.39} & \multirow{2}{*}{$0.53^{\mathrm{ns}}$} \\
\hline Married & 5 & 3.3 & 14 & 8.8 & & \\
\hline \multicolumn{6}{|l|}{ Education } & \\
\hline secondary school & 115 & 76.7 & 120 & 75.0 & \multirow{3}{*}{2.45} & \multirow{3}{*}{$0.12^{\mathrm{ns}}$} \\
\hline Technical school & 35 & 23.3 & 40 & 25.0 & & \\
\hline \multicolumn{5}{|l|}{ Residence } & & \\
\hline Urban & 85 & 56.7 & 90 & 56.2 & \multirow{2}{*}{0.56} & \multirow{2}{*}{$0.43^{\mathrm{ns}}$} \\
\hline Rural & 65 & 43.3 & 70 & 43.8 & & \\
\hline
\end{tabular}

Ns. no Statistical significant differences $\mathrm{P}>0.05$.

Table 4. Comparison between jigsaw and Lecture groups regarding their learning achievement before, immediately after and follow up intervention (4 weeks after intervention) $(n=310)$

\begin{tabular}{|c|c|c|c|c|c|c|c|}
\hline \multirow{2}{*}{ Achievement Levels } & & \multicolumn{2}{|c|}{ jigsaw group $(n=150)$} & \multicolumn{2}{|c|}{ Lecture group $(n=160)$} & \multirow{2}{*}{$\chi^{2}$} & \multirow{2}{*}{ P-value } \\
\hline & & No & $\%$ & No & $\%$ & & \\
\hline \multirow{3}{*}{ Before intervention $^{a}$} & Good & 44 & 29.3 & 43 & 26.9 & \multirow{3}{*}{0.094} & \multirow{3}{*}{0.95} \\
\hline & Pass & 43 & 28.7 & 47 & 29.4 & & \\
\hline & Fail & 63 & 42 & 70 & 43.7 & & \\
\hline \multirow{5}{*}{ Immediately after Intervention } & Excellent & 35 & 23.3 & 26 & 16.3 & \multirow{5}{*}{13.70} & \multirow{5}{*}{$0.04 *$} \\
\hline & Very Good & 55 & 36.7 & 40 & 25 & & \\
\hline & Good & 30 & 20 & 23 & 14.4 & & \\
\hline & Pass & 20 & 13.3 & 54 & 33.7 & & \\
\hline & Fail & 10 & 6.6 & 17 & 10.6 & & \\
\hline \multirow{5}{*}{ Follow Up } & Excellent & 40 & 26.7 & 33 & 20.6 & \multirow{5}{*}{15.29} & \multirow{5}{*}{$0.001 * *$} \\
\hline & Very Good & 60 & 40 & 42 & 26.3 & & \\
\hline & Good & 30 & 20 & 17 & 10.6 & & \\
\hline & Pass & 15 & 10 & 55 & 34.4 & & \\
\hline & Fail & 5 & 3.3 & 13 & 8.1 & & \\
\hline
\end{tabular}

a. there is no excellent or very good level, * no Statistical significant differences $\mathrm{P}>0.05 . *$ Statistical significant differences $\mathrm{P} \leq 0.05, * * *$ highly statistically significant differences $\mathrm{P} \leq 0.001$.

Table 5. Comparison between mean total achievement'scores in both groups before, immediately after and follow up intervention ( $n=310)$.

\begin{tabular}{|c|c|c|c|c|}
\hline Items & jigsaw group $(n=150)$ Mean \pm SD & Lecture group $(n=160)$ Mean \pm SD & Independent test & P-value \\
\hline Before intervention & $21.3 \pm 0.46$ & $21.2 \pm .06$ & 1.58 & 0.06 \\
\hline Immediately after Intervention & $26.5 \pm 0.33$ & $22.8 \pm 0.81$ & 12.66 & $0.001 * *$ \\
\hline Follow Up & $29.1 \pm 0.24$ & $23.5 \pm 0.63$ & 14.84 & $0.001 * *$ \\
\hline
\end{tabular}

**highly statistically significant differences $\mathrm{P} \leq 0.001$. 
Table 6. Distribution of positive students' opinions regarding cooperative jigsaw learning strategy among jigsaw group ( $n=150)$.

\begin{tabular}{lll}
\hline students' opinions & jigsaw group n=150 & No. \\
\hline 1-It made the course content easy for us to understand. & 124 \\
2-It ensured the correction of our misinformation. & 82.7 \\
3-It made us learn better. & 86.7 & 130 \\
4-it increased the possibility of the teacher's interested in each student. & 127 \\
5- The dependence of the students upon the teacher was lessened. & 132 \\
6-It enhanced communication skills \& self-confidence. & 94.7 & 119 \\
7-It enhanced teamwork cooperation. & 79.3 \\
8- Everyone in the group shared responsibility. & 91.3 \\
9-it made the ideas within the group to be discussed more positively. & 96.7 \\
10- It improved critical thinking \& decision making skills. & 137 \\
11-It facilitated applying knowledge into clinical practice. & 127 \\
12-It was the innovative teaching-learning method. & 74.7 \\
13-Overall I am satisfied with this teaching method. & 97.8 & 115 \\
14-Applying jigsaw strategy as a teaching method in other nursing courses " (theory \& practice). & 145 \\
\hline
\end{tabular}

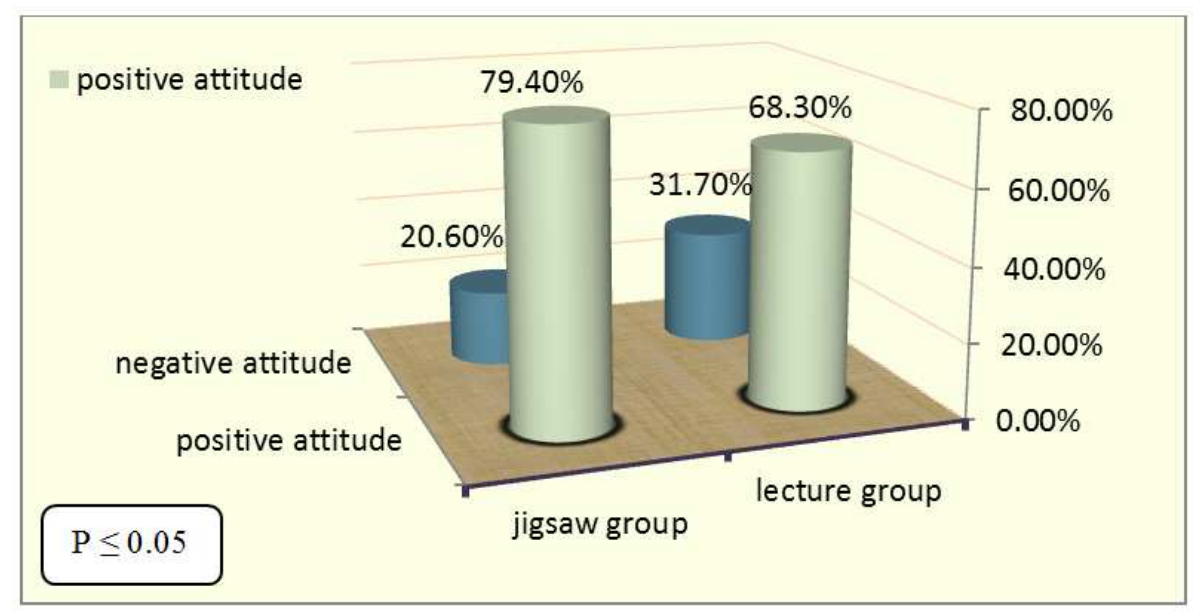

Figure 2. Total attitude score of jigsaw and lecture group after implementation teaching strategies.

Table 7. The correlation coefficient among the jigsaw group's total achievement scores, total attitude and cooperative jigsaw opinions at a different time of assessment $(n=150)$.

\begin{tabular}{lllll}
\hline Variables & Time & Total attitude scores & & \multicolumn{2}{l}{ Total jigsaw opinion`s scores } \\
\hline \multirow{3}{*}{ Total achievements } & Before & $\mathbf{r}$ & p-value & r \\
\cline { 2 - 4 } scores & & 0.537 & $0.000^{* *}$ & 0.642 \\
& Immediately After & 0.467 & $0.000^{* *}$ & $0.000^{* *}$ \\
& up follow & 0.69 & $0.000^{* *}$ & 0.501 \\
\hline
\end{tabular}

**A highly statistically significant difference $(\mathrm{P} \leq 0.001)$.

Table 3: shows, the mean age of the jigsaw and lecture groups were $20.8 \pm 0.54$ and $20.8 \pm 6.53$ respectively with no statistical significance between both groups regarding Sociodemographic characteristics as $\mathrm{p}$-value was $\mathrm{P}>0.05$.

Table 4: notifies that there was no statistical significance between jigsaw and lecture groups before intervention as $\mathrm{p}$ value was $\mathrm{P}>0.05$ while immediately after intervention there was a statistically significant difference between both groups as $p$-value $\leq 0.05$. Moreover, in follow up (4 weeks after intervention) there was a highly statistically significant difference between both groups with $p$-value $\leq 0.001$.

Table 5: portrays that total mean achievement scores were $76.9 \pm 1.03$ in the jigsaw group and $67.5 \pm 1.5$ in the lecture group, with a highly statistically significant difference as the p-value, was $\leq 0.001$.

Figure 2: presents that $79.4 \%$ of the Jigsaw group had a positive attitude regarding Jigsaw strategy in comparison to $68.3 \%$ of the lecture group had a positive attitude regarding the lecture method with a significant statistical difference between both groups as p-value was $\leq 0.05$.

As shown in Table 6: (97.8\%) of the jigsaw group stated that jigsaw method improved critical thinking \& decisionmaking skills and (96.7\%) of them reported that jigsaw learning strategy enhanced teamwork cooperation and (89.3\%) recommended applying jigsaw strategy as a teaching method in other nursing courses "(theory \& practice).

Table 7: emphasizes a highly statistically positive correlation between jigsaw group's total achievement scores and their total attitude and also opinion regarding cooperative jigsaw as a learning strategy before, immediately after and follow up the intervention as $(\mathrm{P} \leq 0.001)$. 


\section{Discussion}

Jigsaw is a well-established strategy for encouraging group sharing and learning of specific content. This technique used as an instructional activity and is best to use when there is a large amount of content to teach and a large number of students to learn [9].

Today, jigsaw strategy has an increasing number of applications in an academic level as it encourages students to listen, cooperate and exchange ideas, also increases learning achievements and performances [19]. Therefore, the present study aimed to evaluate the effect of the utilization of cooperative jigsaw learning strategy on maternity nursing students' attitudes and achievement. Overall, the findings of this study supported the above-mentioned hypotheses.

The present study showed that there was no statistical significance between jigsaw and lecture groups before intervention as $\mathrm{p}$-value was $\mathrm{P}>0.05$ while immediately after intervention there was a statistically significant difference between both groups as $p$-value $\leq 0.05$. Moreover, in follow up (4 weeks after intervention) there was a highly statistically significant difference between both groups with $\mathrm{p}$-value $\leq 0.001$. These results were supported by [20], who reported the average scores of pre-test of control and experiment groups are nearly the same which were (29.03, 30.58) respectively with no statistical difference between the scores of two groups as $p>.05$ and added that the jigsaw method is an active method for improving students' learning of the subject as there was a significant difference between two groups with $\mathrm{p}=.003$ in the post-test scores. Also [21] showed in a study on "the development of cooperative learning using jigsaw activities for learning achievement and self-directed learning behaviors of nursing students" that the learning achievement scores after the jigsaw were statistically significantly higher than before the jigsaw as $(p<0.01)$. furthermore [22] stated a significant difference between experimental (jigsaw) and control (traditional) groups regarding retention test (done at Three weeks after the application) and average scores in favor of the experimental group as $(\mathrm{p}<0.05)$, which reflects the positive effect of jigsaw strategy in the retention of knowledge.

While the above findings disaccordance with [8], who presented that the use of jigsaw had no positive effect on learning and noted this ineffectiveness of this method may pertain to the teachers' unfamiliar with this method as well as lack of competence of teachers in the application of modern teaching methods (such as Jigsaw).

From the researchers' point of view that the above results showed that jigsaw learning strategy improved learning achievements by facilitating critical thinking skills, expressing different thoughts of students, improving communication skills which attentively enhancing the interest for learning and permanent understanding. This will not happen without the presence of a competent teacher, who explains, organize and motivate students to form complete knowledge.

Overall the present study revealed the total mean achievement scores was 76.99 \pm 1.03 in jigsaw group compared to $67.5 \pm 1.5$ in lecture group, with a highly statistically significant difference as $(p \leq 0.05)$ which emphasized the importance of cooperative jigsaw learning strategy toward effective education for nursing students and it can be applied in daily teaching-learning activities. This was in the same line with [23] that studied jigsaw strategy as an active learning method to develop the cognitive and affective domains through curriculam review and revealed that the experimental group performed better than the control group in the domain of knowledge, comprehension, and application. Hence ultimate results of that peer group activity-based learning indicated that it was more effective for teaching nursing students as compared to the traditional lecture method of teaching at the university educational level. This finding supports the first research hypothesis.

Regarding the total attitude score of jigsaw and lecture groups toward the used methods of teaching, the present finding demonstrated that the most of the Jigsaw group had a positive attitude regarding Jigsaw strategy, compared to three-quarters of the lecture group had a positive attitude regarding lecture method with a non-significant difference between both groups. This finding agreed with [16], who investigated students' attitudes toward Jigsaw cooperative learning in the Vietnamese setting of higher education and indicated that students working in cooperative learning groups enjoyed cooperative activities and obtained more knowledge because cooperative learning improved their relationships with their peers, decreased conflict in the group and enhanced their self-esteem. Also, students in the cooperative learning groups felt more interested in learning, and less anxious, perceiving cooperative learning as a valuable way to effectively increase their knowledge.

Also, [3] reported that the students expressed positive attitudes toward jigsaw learning and enjoyed the group spirit and suggested that the Jigsaw strategy helped them become more attentive to the learning process. These similarities between results may be attributed to the interesting of students in preparing lecture information which helped them to think deeply, let them feel more motivated and encourage them to reflect this knowledge on their care in the maternity field more easily. This finding supports the second research hypothesis.

Concerning students' opinions regarding jigsaw strategy, most of the jigsaw group stated that jigsaw strategy improved critical thinking \& decision-making skills enhanced their teamwork cooperation and recommended applying jigsaw strategy as a teaching method in other nursing courses "(theory \& practice). These were consistent with [25], who found in a study comparing traditional lecture versus jigsaw learning methods for teaching medication therapy management that Jigsaw activities enhanced communication skills of nursing students and peer cooperation between Jigsaw groups.

Most studies as [26-28], reported increased satisfaction of the students after utilizing cooperative jigsaw strategy in learning, this positive opinions as a result of improving 
students' self-confidence, self-esteem and various aspects of students' intelligence such as critical thinking \& problemsolving. Also [29], reported that the advantage of the jigsaw method was retention of student's knowledge, refreshment of information and creation of interest in learning.

Additionally [21], concluded in a study on the development of cooperative learning using jigsaw activities for learning achievement and self-directed learning behaviors of nursing students that achievement from studying by themselves promotes students to sustain self-directed lifelong learning and confidence and valued jigsaw activities to be applied in all nursing curriculums.

the current finding revealed, the highly statistically positive relation between jigsaw group's total achievement scores and their total positive attitude and also positive opinions regarding cooperative jigsaw as a learning strategy before, immediately after and follow up the intervention as $(\mathrm{P} \leq 0.001)$. These findings supported that jigsaw was effective in improving learning and promptly bringing more positive attitudes and opinions toward utilizing this method in teaching maternal nursing courses. This was in the same line with [30], who presented that the jigsaw method is one of the most important teaching methods. It improves teamwork and interpersonal communication, thinking, and problem-solving skills. Moreover, it can promote learning among undergraduate students. so teachers are suggested to use jigsaw in their class to improve students' learning.

Finally, the jigsaw has valuable implications for teaching, learning, and nursing educational research, as it is one of the innovative teaching strategies which can be incorporated in the nursing curriculum for the better results and it is a great tool that can be used to enhance and promote higher nursing student achievement.

\section{Conclusion}

Based on the findings of the present study, the hypotheses of the current study were achieved, as students' learning achievement of normal labor lectures were higher scores among jigsaw group than lecture group immediately after intervention with a statistically significant difference and at follow up exam with highly statistically significant differences. Furthermore, Students in the study group had a positive attitude toward the use of jigsaw strategy more than those in the lecture group.

\section{Recommendations}

1. Apply cooperative jigsaw learning strategy as a teaching method in nursing student curriculums.

2. Training workshops should also be conducted for course planners and educators (faculty staff members) to adapt the jigsaw technique as an innovative teaching and learning strategy.

3. Nursing programs need to implement many innovative teaching strategies like a jigsaw to make learning more students centered.
4. Further researches are needed to study the effect of jigsaw learning strategy on clinical achievement, also to explore the obstacles hindering the implementation of the jigsaw learning strategy in nursing education.

\section{Acknowledgements}

The researchers would like to express gratitude and appreciation to maternity nursing students who participated in this study for their interest and effective cooperation.

\section{References}

[1] Haghani F., Rahimi M., Ehsanpour S., (2014): An investigation of perceived feedback in clinical education of midwifery students in Isfahan University of medical sciences. Iranian Journal of Medical Education 2014: 14 (7): 571-580. [In Persian].

[2] Karimi H., Rad M., Bakhshi M., (2013): Do the New Methods of Teaching in Education have Adequate Efficacy? A Systematic Review. SDME 2013; 10 (2): 153-162.

[3] Slavin E., (2011): Instruction Based on Cooperative Learning. In R. E. Mayer \& P. A. Alexander (Eds.), Handbook of Research on Learning and Instruction (pp. 344-360). New York: Taylor \& Francis.

[4] Neurman Y., \& Bekeran Z., (2010): Cultural resources and the gap between theory and practice, Teachers Colleges Record, 103 (3), 417-484.

[5] Harman G., \& Nguyen T., (2010): Reforming teaching and learning in Vietnam's higher education system, Challenges and Priorities (pp. 65-86). London: Springer. http://dx.doi.org/10.1007/978-90-481-3694-0_5.

[6] Sahin A., (2010): Effects of Jigsaw III technique on achievement in written exbeforession. Asia Pacific Education Review, 12 (3), p: 427-435, http://dx.doi.org/10.1007/s12564010-9135-8.

[7] Cağatay G.,\& Demircioğlu G., (2013): The effect of jigsawcooperative learning technique on students' understanding, International Journal of Educational Researchers, 4 (2), 30-37.

[8] Doymus K., Karacop A., Simsek U., (2013): Effects of jigsaw and animation techniques on students understanding of concepts and subjects in electrochemistry, Education tech research journal, NO 58, (67), p: 1-691.

[9] Aronson E., (2011): The jigsaw classroom, London: Retrieved March 27, 2014, from http://www.jigsaw.org.

[10] Crist L., (2012): The Effectiveness of the Jigsaw Approach and Other Cooperative Learning Strategies with Students with Learning Disabilities: A Master's Research Project Beforesented to The Faculty of the Patton College of Education and Human Services, Ohio University.

[11] Hammond L., Flook L., Harvey CH., Barron B. \& Osher D., (2019): implications for the educational practice of the science of learning and development, Journal Applied Developmental Science, ISSN: 1088-8691 (Print) 1532480X (Online) Journal homepage: https://www.tandfonline.com/loi/hads20. 
[12] Fadllaha, N., McKenna, L., (2018): New nurses and community maternal care education: A qualitative study, Elsevier Ltd. available at https: //doi.org/ 10.1016/ j.nepr.11. 011.

[13] Jadhav V., Jadhav, N., (2016): using the jigsaw cooperative learning technique for nursing students: College of Nursing, Navi-Mumbai, India, International Journal of Nursing and Medical Investigation, 1 (2), 130-140.

[14] Benner P., (2014): Excellence and power in clinical nursing practice, Menlo Park, CA: Addison-Wesley Publishing Co., Nursing Division.

[15] Brame C. and Biel R., (2015): Setting up and facilitating group work using cooperative learning groups effectively, Retrieved [today's date] from http://cft.vanderbilt.edu/guidessub-pages/setting-up-and-facilitating-group-work-usingcooperative-learning-groups-effectively.

[16] Tran D., \& Lewis R., (2012): Effects of Cooperative Learning on Students at An Giang University Vietnam, International $\begin{array}{llll}\text { Education } & \text { Studies, } & 5 & \text { (1), }\end{array}$ www.sciedu.ca/ijhehttp://dx.doi.org /10.5539/ies.v5n1p86.

[17] Renganatha L., (2013): A Comparative Study on Effect of Jigsaw Puzzle Method among nursing students' academic level of performance at Oman Nursing Institute, Muscat. Indian J. Appl. Res. 3, 180-182.

[18] Bhandari B., Mehta B., Mavai M., Yogendra R., and Singhal A., (2017): Jigsaw Method; An Innovative Way of Cooperative Learning, Indian journal of physiology and $\begin{array}{llll}\text { pharmacology, } & 61 & \text { (3), } & \text { publication at }\end{array}$ https://www.researchgate.net/publication/318360791.

[19] Fini S., Zarei, E.and Sardare S., (2014): The comparison between the effect on jigsaw 2 and traditional teaching methods on educational achievement. World of Researches Publication, 3 (1), 22-26.

[20] Abdullah A., Biyikli F., (2017): The Effect of Jigsaw Technique on the Students' Laboratory Material Recognition and Usage Skills in General Physics Laboratory Course, Universal Journal of Educational Research, 5 (7), p: 1073, http://www.hrpub.org.

[21] Kritpracha C., Sae-Sia W., Nukaew O., Jittanoon P., Chunuan S., and Kaosaiyaporn O., (2018): The Development of
Cooperative Learning Using Jigsaw Activities for Learning Achievement and Self-directed Learning Behaviors of Nursing Students, International Journal of Information and Education Technology, Vol. 8, No. 12, December 2018.

[22] Tekdal m., Sonmez s., (2018): The Effect of Using Jigsaw Cooperative Learning Technique in Teaching Computer Literacy on Students' Achievement and Retention, Çukurova Üniversitesi Eğitim Fakültesi Dergisi, 47 (1), 2018, 37-59, www.cufej.com.

[23] Wong C., (2016): A modified jigsaw method: an active learning strategy to develop the cognitive and affective domains through curricular review, Physical Therapy Education J, No 22 (1), 15, p33.

[24] Wilson J., Pegram H., Battise D., and Robinson M., (2017): Traditional lecture versus jigsaw learning method for teaching medication therapy management (MTM) core elements, Currents in Pharmacy Teaching and Learning, vol. 9, pp. 1151-1159.

[25] Eslamian H., Saeedi R., Fatahi Y., (2013): Comparison of the effectiveness of teaching methods of group discussion and lecture on learning and satisfaction of students inteaching of religion and life courses in Dubai Curriculum, knowledge and research J., NO 11 (38); pp: 13- 23.

[26] Mbacho N. \& Changeiywo M., (2014): Effects of Jigsaw Cooperative Learning Strategy on Students' Achievement by Gender Differences in Secondary School, Research in curriculum planning J., 11 (15): 55-67.

[27] Yazdanpoor N., Yusefi AR. and Haghani F., (2016): The effect of education on student achievement through collaborative projects and experimental third girl Fouladshahr in statistics and modeling. Curriculum planning knowledge and research, 25: 85-97.

[28] Sagsoz O., Karatas O., Turel V., Yildiz M., and Kaya E., (2017): "Effectiveness of jigsaw learning compared to lecturebased learning in dental education," Journal of American Medical, vol. 21, pp. 28-32.

[29] Moonaghi H., Bagher M., (2017): Jigsaw: A good studentcentered method in medical education, Future Of Medical Education Journal (Fmej), 7; 1, p; 39, mums.ac.ir/j-fmej March 25. 